\title{
Localization of Nogo-A and Nogo-66 Receptor Proteins at Sites of Axon-Myelin and Synaptic Contact
}

\author{
Xingxing Wang, ${ }^{1}$ Soo-Jin Chun, ${ }^{4}$ Helen Treloar, ${ }^{2}$ Timothy Vartanian, ${ }^{4}$ Charles A. Greer, ${ }^{2,3}$ and \\ Stephen M. Strittmatter ${ }^{1,3}$ \\ Departments of ${ }^{1}$ Neurology and ${ }^{2}$ Neurosurgery and ${ }^{3}$ Section of Neurobiology, Yale University School of Medicine, \\ New Haven, Connecticut 06510, and ${ }^{4 H a r v a r d ~ I n s t i t u t e s ~ o f ~ M e d i c i n e, ~ B o s t o n, ~ M a s s a c h u s e t t s ~} 02115$
}

Axon regeneration in the adult CNS is limited by the presence of inhibitory proteins. An interaction of Nogo on the oligodendrocyte surface with Nogo-66 Receptor ( $\mathrm{NgR}$ ) on axons has been suggested to play an important role in limiting axonal growth. Here, we compare the localization of these two proteins immunohistochemically as a test of this hypothesis. Throughout much of the adult CNS, Nogo-A is detected on oligodendrocyte processes surrounding myelinated axons, including areas of axon-oligodendrocyte contact. The $\mathrm{NgR}$ protein is detected selectively in neurons and is present throughout axons, indicating that Nogo-A and its receptor are juxtaposed along the course of myelinated fibers. $\mathrm{NgR}$ protein expression is restricted to postnatal neurons and their axons. In contrast, Nogo-A is observed in myelinating oligodendrocytes, embryonic muscle, and neurons, suggesting that Nogo-A has additional physiologic roles unrelated to $\mathrm{NgR}$ binding. After spinal cord injury, Nogo-A is upregulated to a moderate degree, whereas $\mathrm{NgR}$ levels are maintained at constant levels. Taken together, these data confirm the apposition of Nogo ligand and $\mathrm{NgR}$ receptor in situations of limited axonal regeneration and support the hypothesis that this system regulates CNS axonal plasticity and recovery from injury.

Key words: axon regeneration; axonal growth cone; myelin; plasticity; skeletal muscle; axon repulsion
Many forms of injury to the adult nervous system spare neuronal cell bodies but sever their axonal connections. Recovery of function is then dependent on axonal regeneration. Although adult mammalian CNS neurons exhibit a capacity for axonal outgrowth in permissive environments, the injured adult CNS contains axon-inhibitory factors limiting anatomical and functional recovery (Richardson et al., 1980; David and Aguayo, 1981; Benfey and Aguayo, 1982; Fournier and Strittmatter, 2001). The CNS myelin component is especially hostile to axonal outgrowth, and Nogo-A is a prominent myelin-derived inhibitor of axonal outgrowth (Chen et al., 2000; GrandPre et al., 2000; Prinjha et al., 2000). An understanding of the cellular and subcellular distribution of the Nogo protein in oligodendrocytes is crucial to any consideration of its pathologic role in limiting axonal regeneration.

Nogo is expressed in three isoforms derived from alternate promoter and splice usage (Chen et al., 2000; Fournier et al., 2000; GrandPre et al., 2000; Prinjha et al., 2000). Nogo-A, -B, and - $\mathrm{C}$ proteins share a $\mathrm{C}$ terminal region related to the Reticulon family of proteins. Previous work has demonstrated that in adult rodents, Nogo-A mRNA is expressed quite selectively in oligodendrocytes and certain neurons with little peripheral expression (Chen et al., 2000; GrandPre et al., 2000). Nogo-B and Nogo-C mRNA are expressed more widely with more prominent neuronal expression and skeletal muscle expression.

The cellular distribution of Nogo protein has been only partly

\footnotetext{
Received Feb. 7, 2002; revised April 8, 2002; accepted April 15, 2002.
}

This work was supported by research grants from the National Institutes of Health (S.M.S., C.A.G.) and from the McKnight Foundation and the Institute for the Study of Aging and Biogen, Inc. (S.M.S.). S.M.S. is an Investigator of the Patrick and Catherine Weldon Donaghue Medical Research Foundation.

Correspondence should be addressed to Dr. Stephen M. Strittmatter, Department of Neurology, Yale University School of Medicine, P. O. Box 208018, 333 Cedar Street, New Haven, CT 06520. E-mail: stephen.strittmatter@yale.edu.

Copyright (C) 2002 Society for Neuroscience $0270-6474 / 02 / 225505-11 \$ 15.00 / 0$ defined. In transfected epithelial cells, Nogo-A and -C are concentrated in the endoplasmic reticulum with a small percentage of the protein at the cell surface (GrandPre et al., 2000). The surface epitope is a 66 amino acid (aa) loop separating two hydrophobic segments near the $\mathrm{C}$ terminus and is common to Nogo- $\mathrm{A},-\mathrm{B}$, and $-\mathrm{C}$. The $\mathrm{N}$ and $\mathrm{C}$ termini of the protein are cytosolic in transfected cells. In cultured oligodendrocytes, the 66 aa loop can be detected at the cell surface as well (GrandPre et al., 2000). The distribution of the protein in brain tissue is not well described.

The 66 aa surface loop of Nogo is inhibitory for axonal growth in culture and acts via a Nogo-66 Receptor ( $\mathrm{NgR}$ ) expressed by neurons and localized to their axons in vitro (GrandPre et al., 2000; Fournier et al., 2001). Although it is clear that the $\mathrm{NgR}$ mRNA is expressed selectively in adult neurons, $\mathrm{NgR}$ protein distribution in vivo has not been considered. It has been hypothesized that interactions between Nogo and NgR limit both axonal plasticity and regeneration (Thallmair et al., 1998; Brittis and Flanagan, 2001; Fournier et al., 2001). For this hypothesis to be tenable, there must be localized expression of $\mathrm{NgR}$ on the surface of axons and Nogo on the adaxonal surface of myelin. Here, we use immunohistologic methods to localize Nogo-A and $\mathrm{NgR}$ in mouse tissues. The data confirm the opposing distributions of this ligand-receptor pair at the myelin-axon interface and support the hypothesis that Nogo restricts axonal sprouting in the adult nervous system.

\section{MATERIALS AND METHODS}

Antibodies. The polyclonal anti-NgR antibody was raised against a GSTmouse $\mathrm{NgR}$ fusion protein and has been described (Fournier et al., 2001). Anti-Nogo-A antibody was generated by immunizing rabbits with KLH-conjugated peptide SYDSIKLEPENPPPYEEA, corresponding to aa $623-640$ of rat Nogo-A. The antibody was affinity purified on a peptide-agarose resin before immunostaining protocols. 


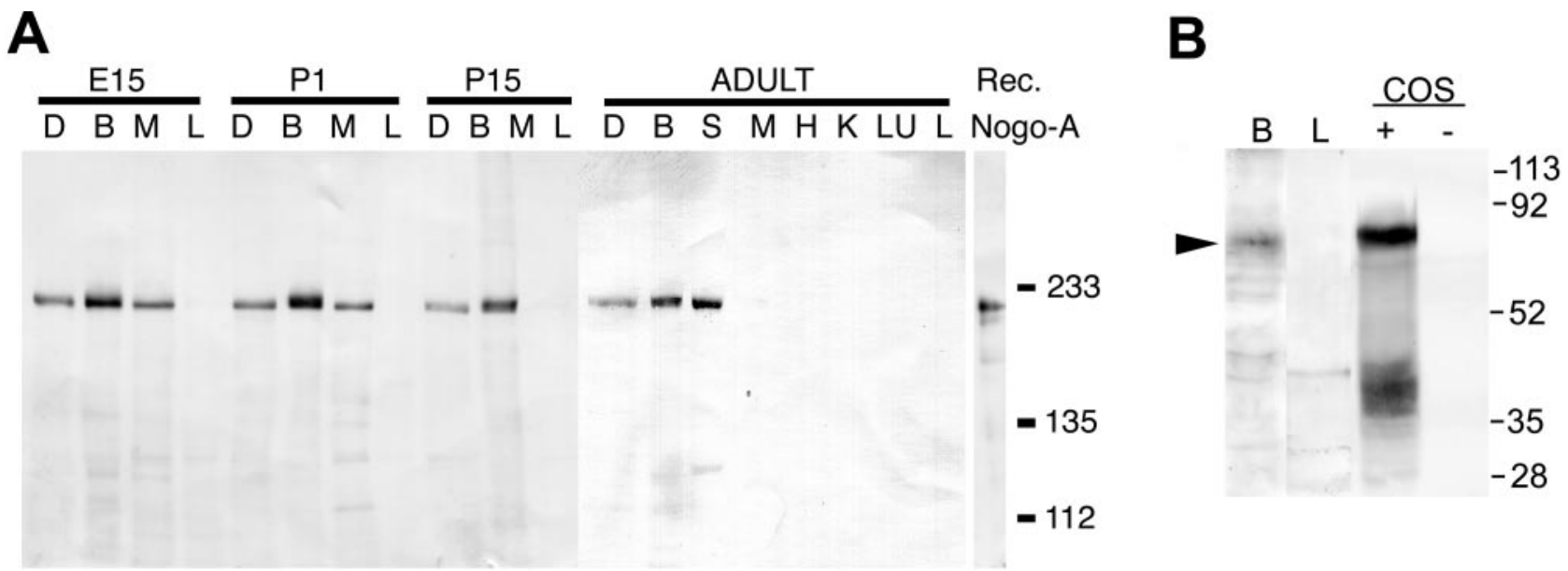

Figure 1. Immunoblot of Nogo-A and $\mathrm{NgR}$ expression in mouse tissues. $A$, Samples $(20 \mu \mathrm{g})$ from the indicated tissues from mice of the indicated ages were analyzed by anti-Nogo-A immunoblot. $D$, Dorsal root ganglion; $B$, brain; $S$, spinal cord; $M$, skeletal muscle; $H$, heart; $K$, kidney; $L U$, lung; $L$, liver. The migration of recombinant Nogo-A is shown at right with molecular weight standards of 233,135 , and $112 \mathrm{kDa}$. $B$, Immunoblot for NgR in adult mouse brain $(B)$, adult liver $(L), \mathrm{NgR}$-expressing COS cells $(\mathrm{COS},+)$, or control COS cells $(\mathrm{COS},-)$. Molecular weight standards are indicated at the right, in kilodaltons.

Immunohistochemistry. C57BL/6 mice (Charles Rivers Laboratories, Wilmington, MA) of embryonic day 15 (E15), postnatal day 1 (P1), P15, and adult stages were used in this study. The animals were anesthetized intraperitoneally with $2.5 \%$ avertin and were then perfused transcardially with 0.1 M PBS followed by $4 \%$ paraformaldehyde. Different tissues were dissected and postfixed in $4 \%$ paraformaldehyde in $0.1 \mathrm{M}$ PBS. We cut $40-50 \mu \mathrm{m}$ sections on a vibrating microtome. Before staining, free- floating sections were incubated sequentially in $0.3 \%$ Triton $\mathrm{X}-100$ in PBS (PBS-T; $30 \mathrm{~min}), 10 \%$ goat serum in PBS (30 min), and then with primary antibodies (anti-Nogo-A, 1:8000 or anti-NgR, 1:8000; $4^{\circ} \mathrm{C}$ for 24 $\mathrm{hr}$ ). After rinsing with PBS, diluted biotinylated anti-rabbit IgG was used as a secondary antibody (1:2000; Vector Laboratories, Burlingame, CA). Sections were developed in diaminobenzidine (DAB kit; Vector Laboratories), mounted, air-dried, dehydrated, and coverslipped.
Figure 2. Localization of Nogo-A and NgR in adult mouse spinal cord. Adult mouse thoracic spinal cord sections were sectioned in the transverse or sagittal plane and stained with anti-Nogo-A or anti-NgR antiserum, as indicated. Note the oligodendrocyte staining (arrowhead) for Nogo-A and the staining along axonal profiles for both proteins (arrows). In some cases, $50 \mu \mathrm{g} / \mathrm{ml}$ of purified antigen peptide or protein was included together with primary antibody (Antigen blockade). Scale bar, $100 \mu \mathrm{m}$.
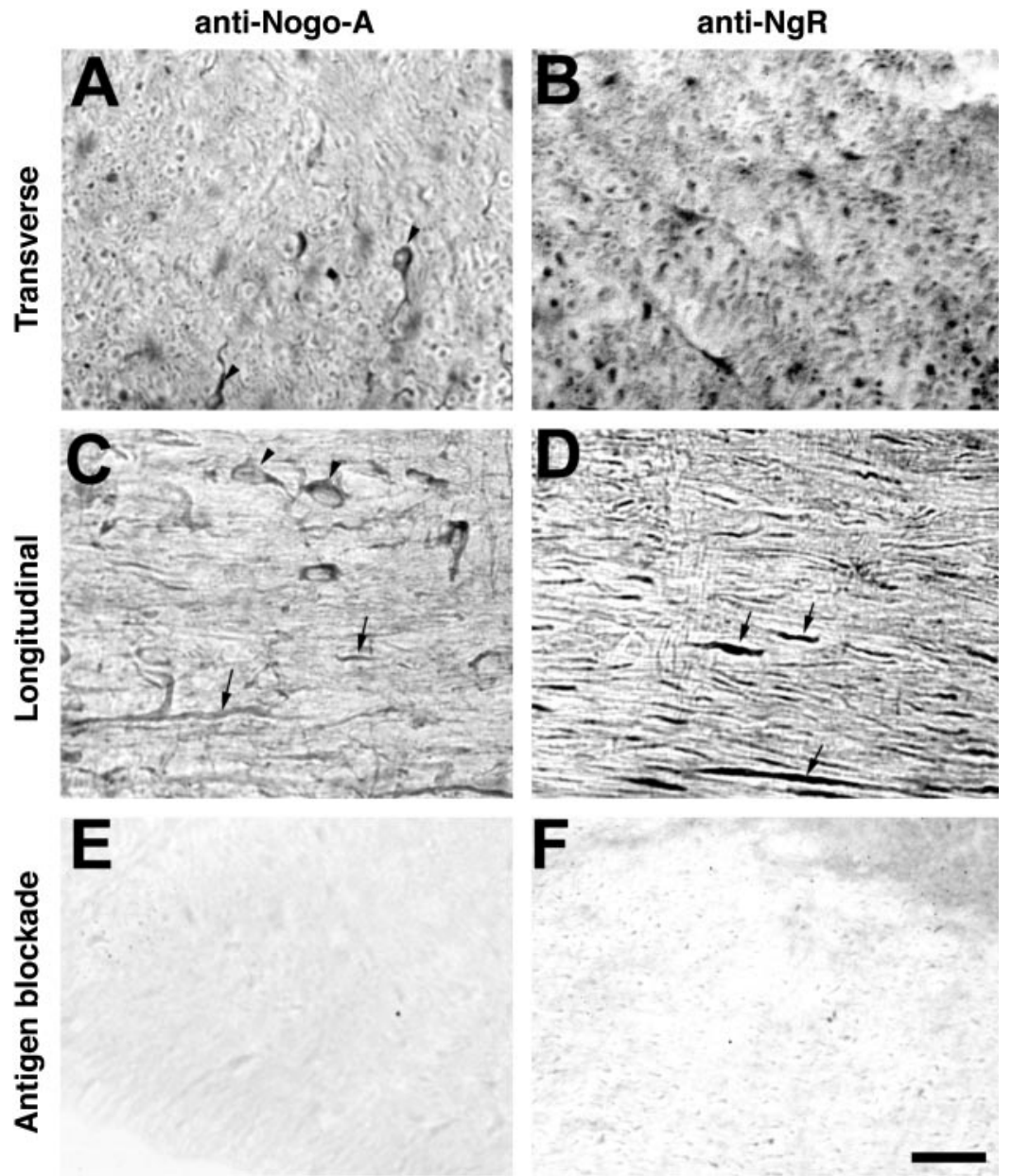

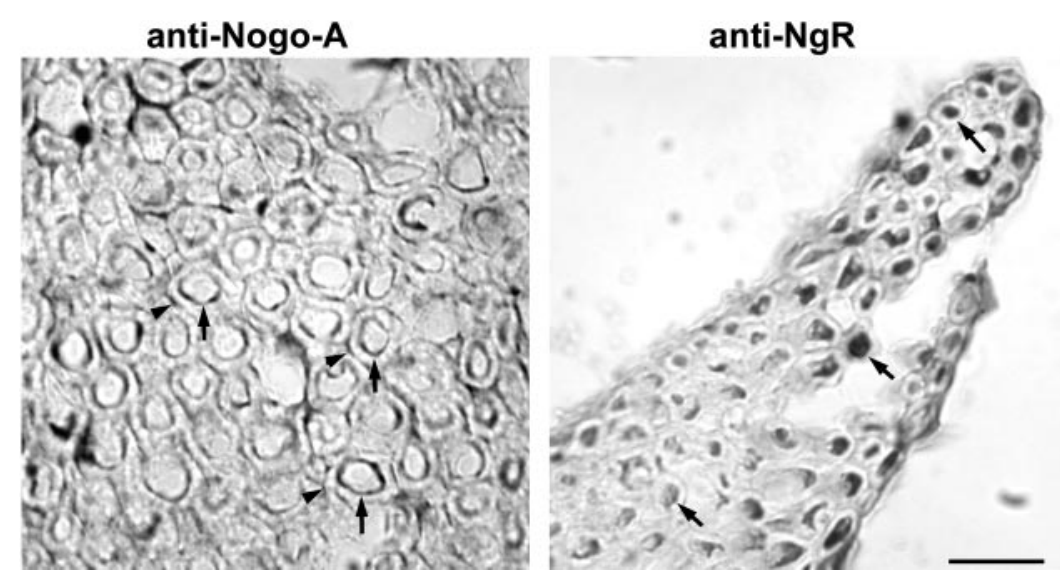

Figure 3. Nogo-NgR distribution in ventral spinal roots. Cross sections of lumbar ventral roots stained with the antiNogo-A and anti-NgR antibodies. Note the axonal staining for $\mathrm{NgR}$ (arrows in right panel) and the myelin staining for Nogo-A, detectable at the outer (arrowheads in left panel) and adaxonal (arrows in left panel) surface of the myelin. Scale bar, $100 \mu \mathrm{m}$.
Double immunofluorescence. The following monoclonal primary antibodies were used in combination with the anti-Nogo-A or anti-NgR antibodies: anti-CNPase monoclonal antibody (clone 11-5B, 1:500; Promega, Madison, WI) and $\beta$-III tubulin monoclonal antibody (1:1000; Covance, Denver, PA). After incubating in the primary antibodies for 24 $\mathrm{hr}$, sections were washed in PBS and then incubated for $1 \mathrm{hr}$ at room temperature with anti-rabbit IgG (FITC-conjugated, developed in goat, 1:200; Sigma, St. Louis, MO) and anti-mouse IgG (TRITC-conjugated, developed in goat, 1:200; Sigma). Confocal analysis of staining was obtained with a Zeiss LSM-5 system.

Immunoblots. Protein extracts from different tissues $(20 \mu \mathrm{g})$ were electrophoresed through a SDS-polyacrylamide gel and transferred to a

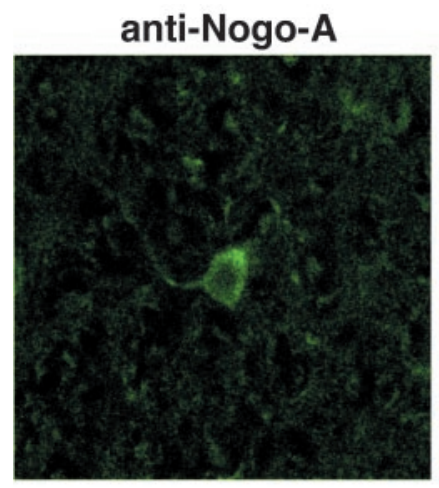

anti-Nogo-A

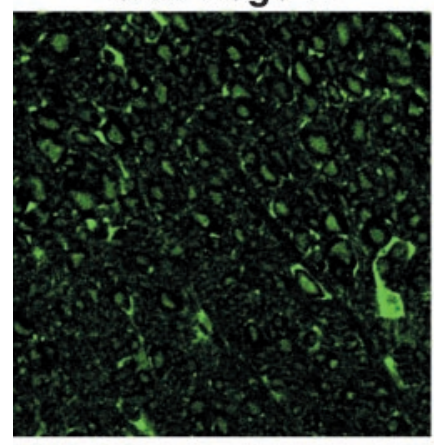

anti-NgR

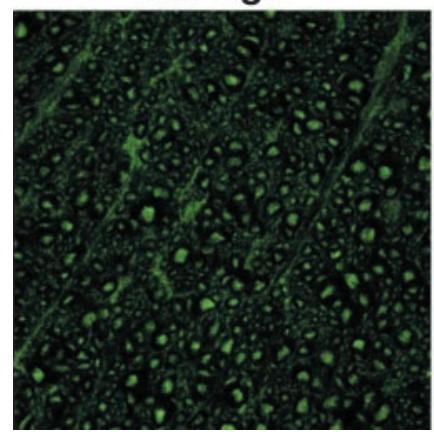

anti-CNPase

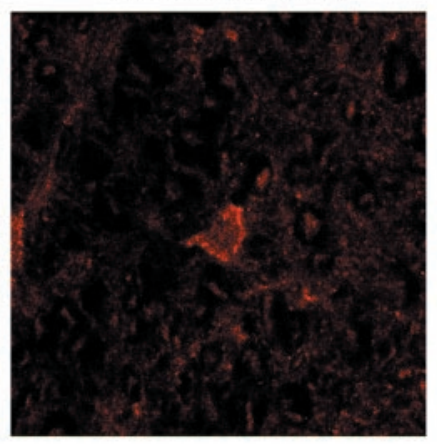

anti-tubulin

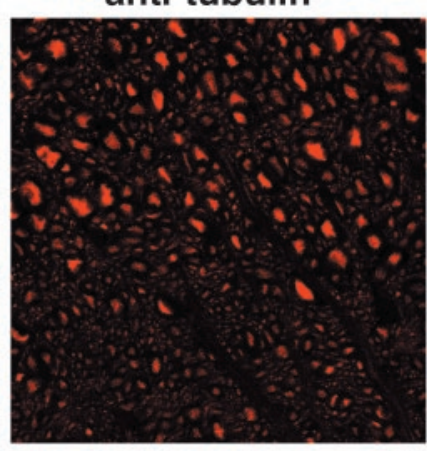

anti-tubulin

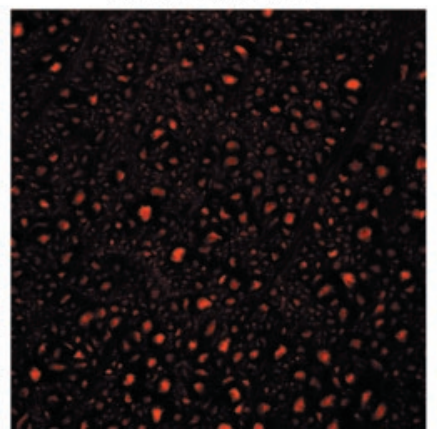

\section{merged}

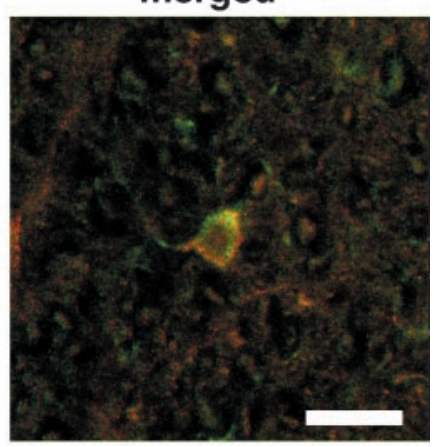

merged

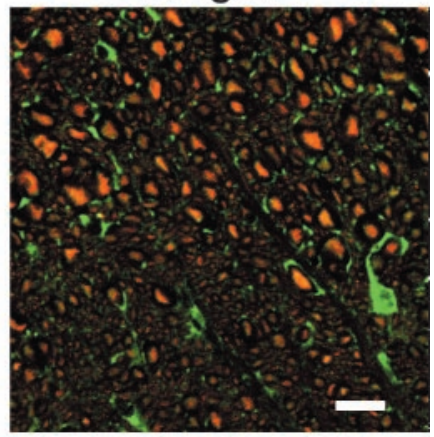

merged

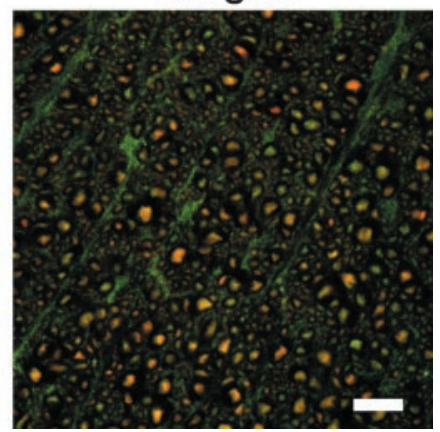

Figure 4. Cellular localization of NogoA and NgR. Transverse sections of the adult spinal cord were processed for antiNogo-A/anti-CNPase (top panels), antiNogo-A/anti- $\beta$-III tubulin (middle panels), or anti-NgR/anti- $\beta$-III tubulin staining (bottom panels) and examined by confocal microscopy. Note the colocalization of Nogo-A with CNPase and $\mathrm{NgR}$ with $\beta$-III tubulin. Strong oligodendrocyte Nogo-A immunoreactivity surrounds axonal staining. Scale bars, $100 \mu \mathrm{m}$. 

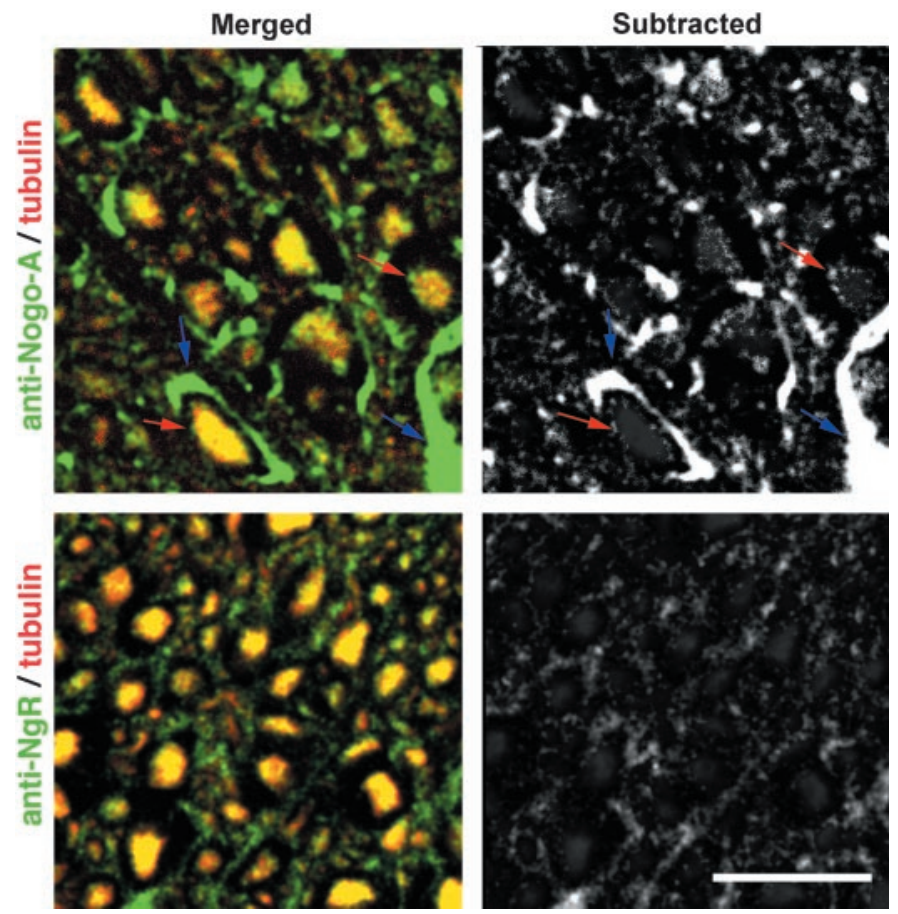

Figure 5. Relationship of Nogo-A and NgR immunoreactivity to axons. Sections stained with anti-Nogo-A or anti-NgR (green) plus anti- $\beta$-III tubulin $(r e d)$ as in Figure 4 are presented as higher magnification merged images (merged) or with the $\beta$-III tubulin signal subtracted from the Nogo-A or NgR signal (subtracted). For Nogo-A, but not for NgR, note the rim of staining at the inner (red arrow) and outer (blue arrow) circumference of the myelin. Scale bar, $100 \mu \mathrm{m}$.

polyvinylidene difluoride membrane. After the transfer, the membranes were incubated overnight at $4^{\circ} \mathrm{C}$ with the anti-Nogo-A antibody (1: 10,000). The secondary antibody anti-rabbit IgG (alkaline phosphatase conjugate, 1:5000; Sigma). Nogo-A-transfected Cos-7 cells were used as a control (GrandPre et al., 2000). For NgR, membrane fractions were treated with $4 \%$ paraformaldehyde for $20 \mathrm{~min}$ and washed, before immunoblotting with anti-NgR antiserum (1:3000; Fournier et al., 2001).

Electron microscopy. Animals were perfused, and vibratome sections stained as for routine immunohistology except that the fixative was $0.5 \%$ glutaraldehyde plus $4 \%$ paraformaldehyde. Triton X-100 was omitted from all steps, but to increase tissue penetration of antibodies, the vibratome sections underwent a rapid freeze-thaw cycle before staining. After the peroxidase reaction, tissue was counterstained with osmium tetroxide and embedded for thin sectioning in acrylite between plastic coverslips. Sections of $100 \mathrm{~nm}$ were examined on a Phillips transmission electron microscope

Oligodendrocyte differentiation. Oligodendrocyte precursor cells were isolated from P2 rat brain and differentiated in vitro (Vartanian et al., 1997). Staining with stage-dependent antigens followed previous protocols (Vartanian et al., 1997).

\section{RESULTS}

To provide immunohistologic analysis of Nogo-A, an affinitypurified anti-peptide antibody was generated. By immunoblot, this preparation specifically detects recombinant human Nogo-A and mouse brain Nogo-A of 215 kDa (Fig. 1). In adult mouse samples, Nogo-A protein level is high in adult brain and spinal cord, lower in dorsal root ganglia, and undetectable in heart, liver, lung, and kidney. Skeletal muscle expresses Nogo-A during the E15 and P1 developmental stages, but no muscle expression is detectable in P15 or adult samples. These findings are consistent with previous mRNA studies of Nogo-A (Chen et al., 2000; GrandPre et al., 2000). Anti-NgR immunoblots of aldehydetreated tissues demonstrate a prominent band of $80 \mathrm{kDa}$ in adult
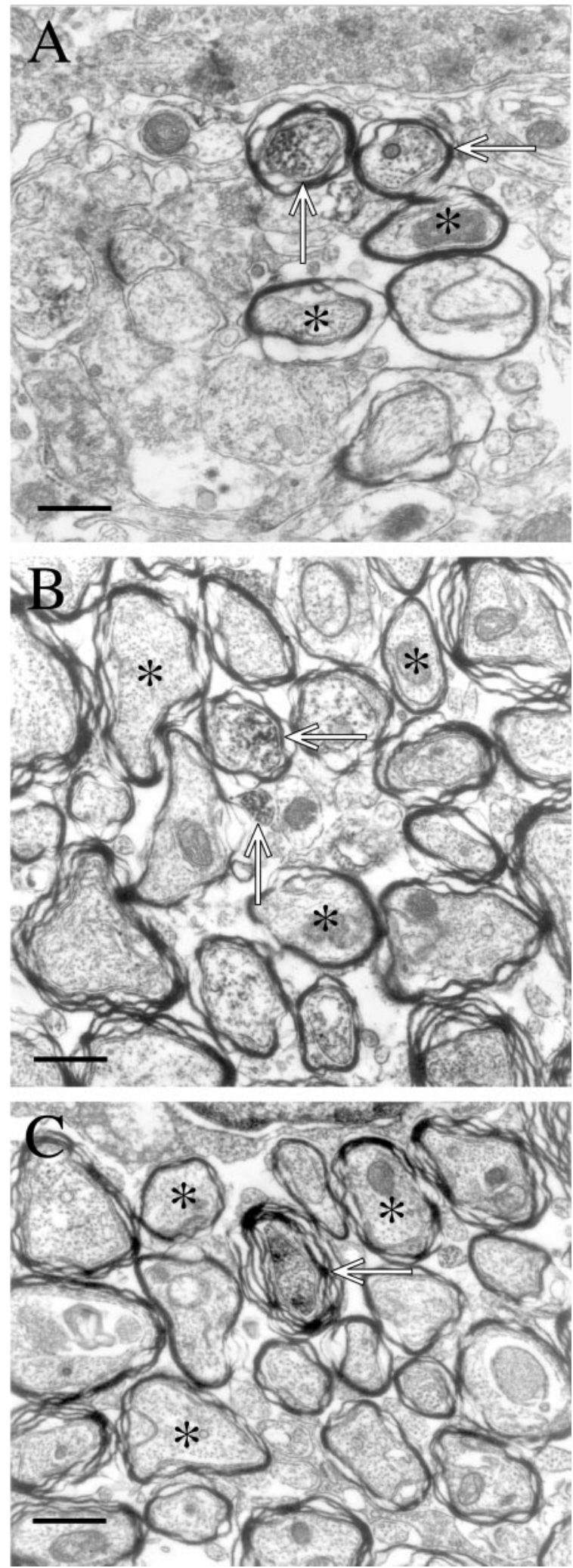

Figure 6. Ultrastructural localization of $\mathrm{NgR}$ to axons. In $A$, labeled axons in cortex, apparent because of the accumulation of reaction product within the axon, are shown (open arrows). Myelin membranes are dense in these pictures because of the osmium treatment, and this density is present in samples not stained with anti-NgR. It is the electron-dense reaction product within the axons that is $\mathrm{NgR}$-selective. Unlabeled axons are also within the field of view (asterisks). In $B$ and $C$, both labeled (arrows) and unlabeled (asterisks) are seen. Scale bars: $A, B, 5 \mu \mathrm{m} ; C, 6 \mu \mathrm{m}$. 


\begin{tabular}{llcc}
\hline \multicolumn{3}{l}{ Table 1. Nogo-A and NgR protein distribution in adult mouse CNS } \\
Region & Subregion & Nogo-A & NgR \\
\hline Cerebral cortex & Frontal & ++ & ++ \\
& Parietal & ++ & ++ \\
Hippocampus & Occipital & ++ & ++ \\
& CA1 & + & ++ \\
Amygdala & DG & + & ++ \\
Thalamus & & + & ++ \\
Corpus callosum & & + & ++ \\
Caudate-putamen & & +++ & ++ \\
Substantia nigra & & +++ & + \\
Cerebellum & Molecular layer & ++ & ++ \\
& Purkinjie cell layer & - & ++ \\
Spinal cord & Granular cell layer & ++ & ++ \\
& Gray matter & + & ++ \\
& White matter & ++ & ++ \\
\end{tabular}

The relative levels of Nogo- $\mathrm{A}$ and $\mathrm{NgR}$ protein were assessed qualitatively from immunohistologic experiments as in Figures 2-9. The level of protein is represented by the following scale: + , weak; ++ , medium; +++ , strong; - , not detectable. mouse brain and transfected COS cells, but not in adult mouse liver or untransfected COS cells (Fig. $1 B$ ).

The distributions of Nogo-A and NgR were examined in adult mouse spinal cord sections (Fig. 2). Immunostaining for both proteins is detected in white matter, and this staining is blocked by inclusion of purified antigen in the incubation (Fig. 2E,F). Nogo-A-positive cells detected in the white matter have the appearance of oligodendrocytes, and their processes are well stained (Fig. 2A,C). Transverse sections of the cord (Fig. 2A) reveal Nogo-A at the outer circumference of myelin sheaths but also suggest that Nogo-A is present at the inner adaxonal circumference of myelin. Nogo-A protein is also observed at lower levels within axonal profiles. NgR protein is not found in oligodendrocytes or the outer myelin sheath but is detected in axons surrounded by myelin (Fig. 2B,D). In longitudinal sections (Fig. $2 C, D$ ) and in teased fiber preparations (data not shown), the Nogo-A and NgR protein distributions extend along the myelinated fibers. Neither protein appears to be confined selectively to internodal or paranodal regions.
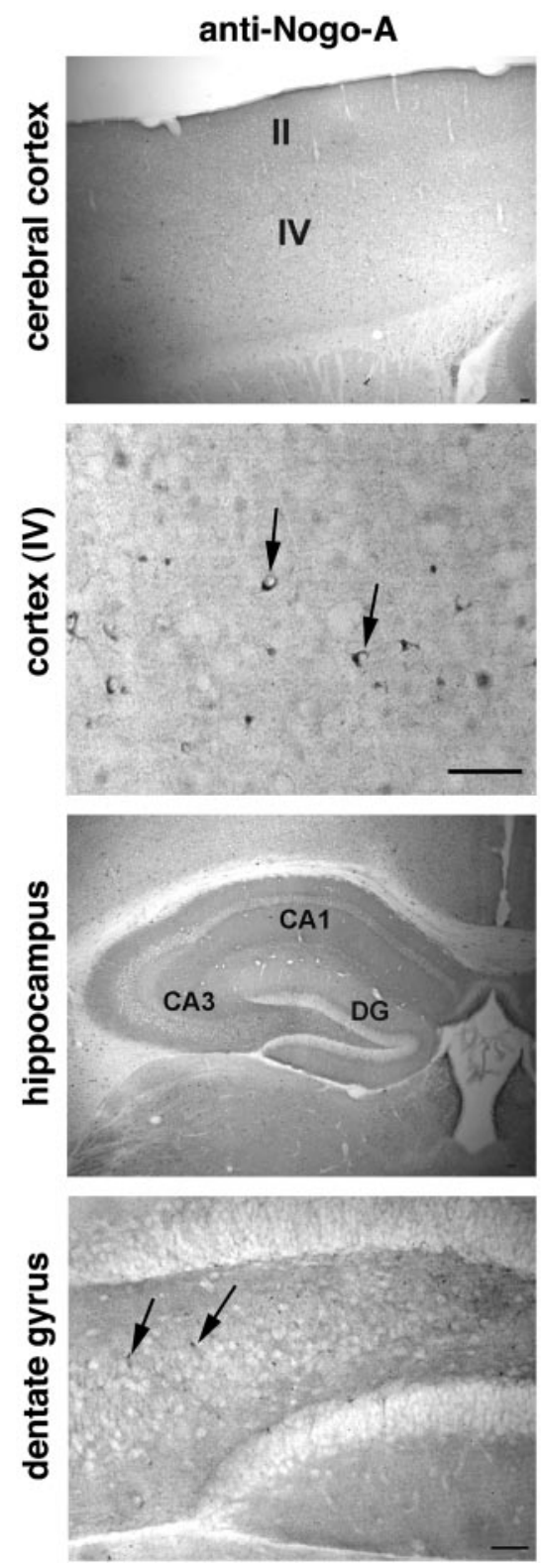

anti-NgR
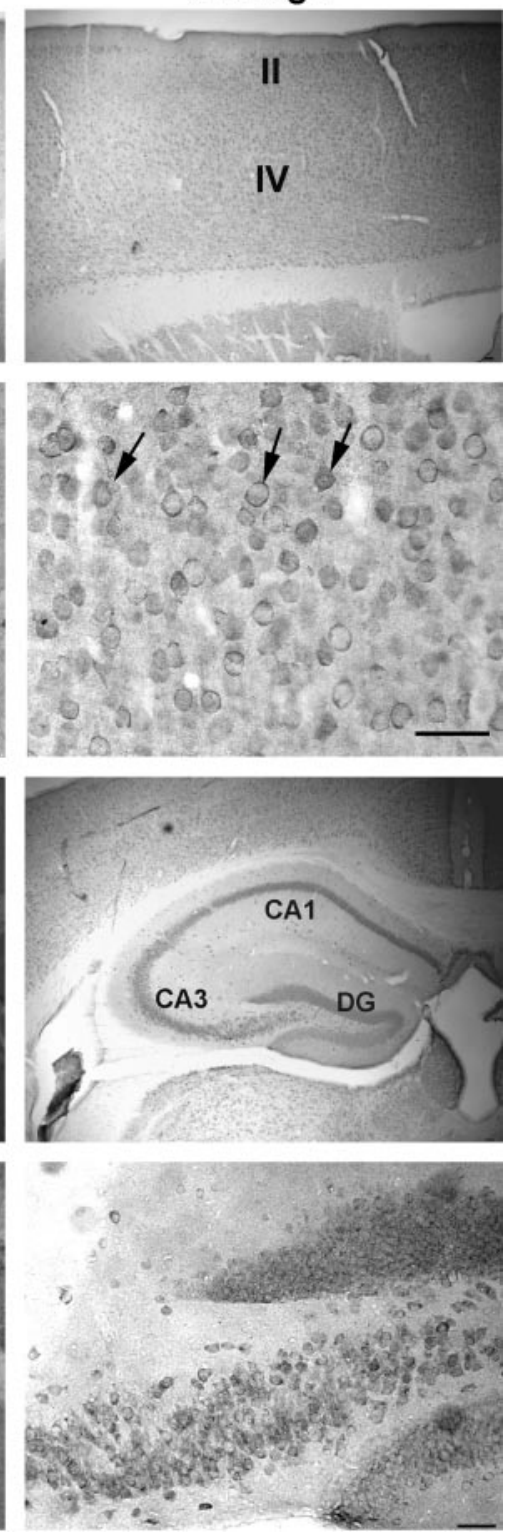

Figure 7. Nogo-A and NgR in the adult forebrain. Coronal sections of adult mouse brain were examined for anti-Nogo-A and anti-NgR staining. Note the small oligodendrocyte cell bodies (arrows) and neuropil staining for Nogo-A, and the multiple neuronal cell bodies (arrows) and neuropil staining for $\mathrm{NgR}$. The abbreviations are: $I I$ and $I V$, layers II and IV of the cortex; $C A 1$ and $C A 3$, pyramidal cell layers of the hippocampus; $D G$, dentate gyrus of the hippocampus. Scale bars, 100 $\mu \mathrm{m}$. 

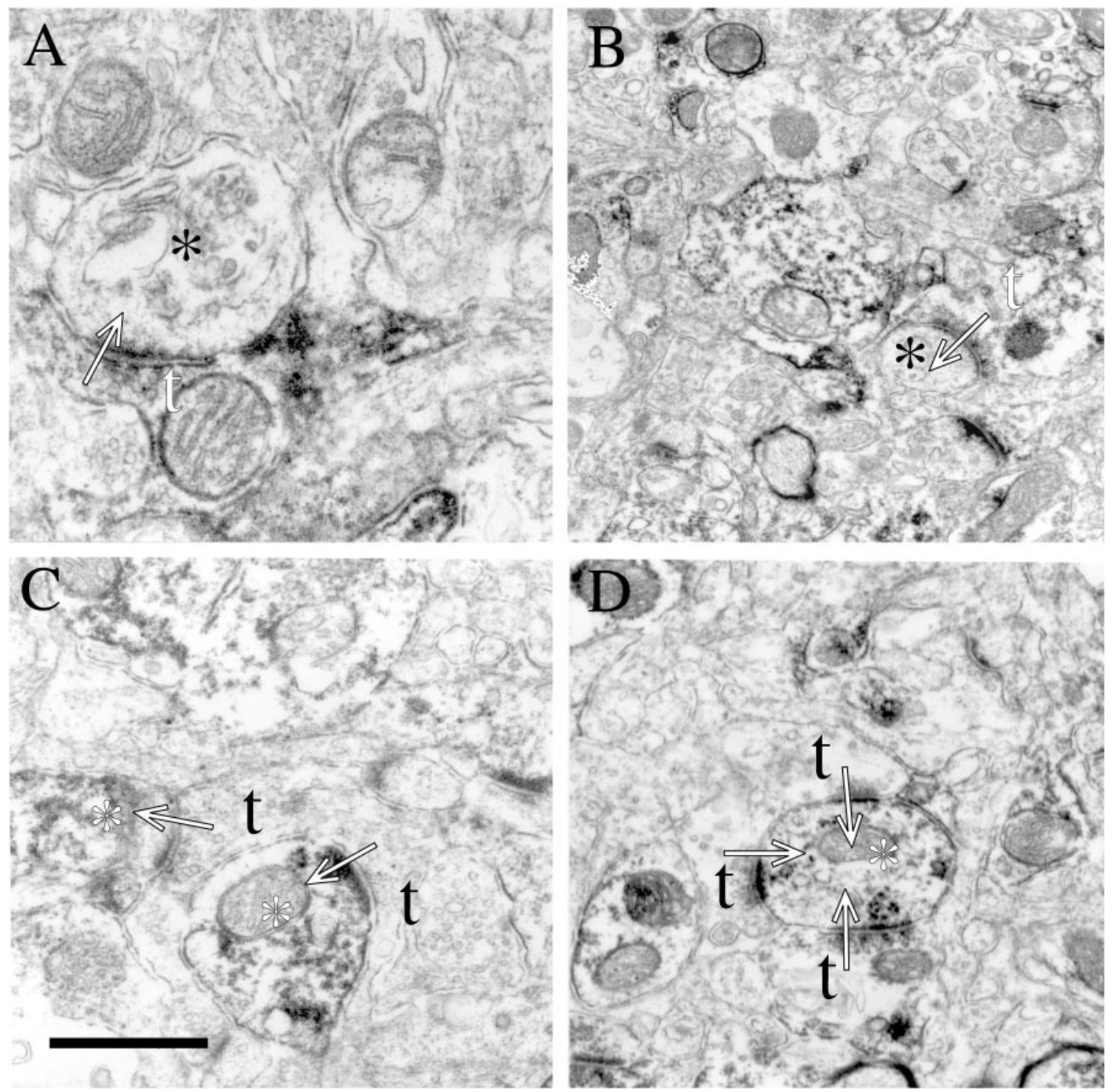

Figure 8. NgR localizes to both presynaptic and postsynaptic profiles in cortex. In $A$ and $B$, labeled presynaptic terminals (white $t$ ) are seen making asymmetric synapses (arrows) onto unlabeled processes (black asterisks). In $C$ and $D$, unlabeled presynaptic terminals (black $t$ ) are seen making asymmetric synapses (arrows) onto labeled processes (white asterisk). In all examples, small accumulations of spherical vesicles are observed in the presynaptic terminal while a thick postsynaptic specialization characterizes the postsynaptic element. Scale bar (shown in $C$ ): $A$, $0.5 \mu \mathrm{m} ; B, 1.3 \mu \mathrm{m} ; C$, $0.75 \mu \mathrm{m} ; D, 1.0 \mu \mathrm{m}$.

The differential distribution of the proteins is even more obvious in transverse sections of ventral lumbar roots where axonal Nogo-A is less prominent. The presence of Nogo-A at both the outer and the inner adaxonal sheath of myelin is apparent (Fig. 3). $\mathrm{NgR}$ protein is clearly localized to the axon but not the myelin.

To verify the cellular origin and relative juxtaposition of Nogo-A and $\mathrm{NgR}$, sections were double labeled for these proteins and either an oligodendrocyte marker, CNPase, or an axonal marker, $\beta$-III tubulin (Fig. 4). Clearly, the Nogo-A-positive cells in spinal cord white matter are CNPase-positive, confirming the oligodendrocyte origin of Nogo-A. In double stains for $\beta$-III tubulin and Nogo-A, the presence of low level Nogo-A in axons surrounded by higher level Nogo-A in oligodendrocyte processes is verified. The $\mathrm{NgR}$ staining matches precisely with the $\beta$-III tubulin staining, confirming its neuronal origin.

The juxtaposition of oligodendrocyte Nogo-A with axonal $\mathrm{NgR}$ was investigated by two additional methods, higher magnification analysis of confocal images and ultrastructural analysis. The Nogo-A/ $\beta$-III tubulin double-stained images exhibit a rim of Nogo-A staining that extends circumferentially beyond the axonal $\beta$-III tubulin staining (Fig. 5). When the $\beta$-III tubulin stain is digitally subtracted from the Nogo-A stain, this rim of staining is obvious. In contrast, the $\mathrm{NgR}$ immunoreactivity precisely matches that for $\beta$-III tubulin.

Ultrastructural examination of $\mathrm{NgR}$ localization confirms these impressions (Fig. 6). NgR is present in myelinated axonal profiles in cortex (Fig. 6A) as well as spinal cord (Fig. 6B,C). The HRP reaction product is not limited to the plasmalemma, but is spread throughout the axon where it often labels heavily microtubules and intracellular organelles. Although many unlabeled axons are also present, it is not clear if these are indicative of axons that lack $\mathrm{NgR}$ or if this is a reflection of the difficulty of examining $\mathrm{NgR}$ labeling at the ultrastructural level. In a few cases, small unmyelinated axons also express $\mathrm{NgR}$ (Fig. 6B). Overall, this analysis 

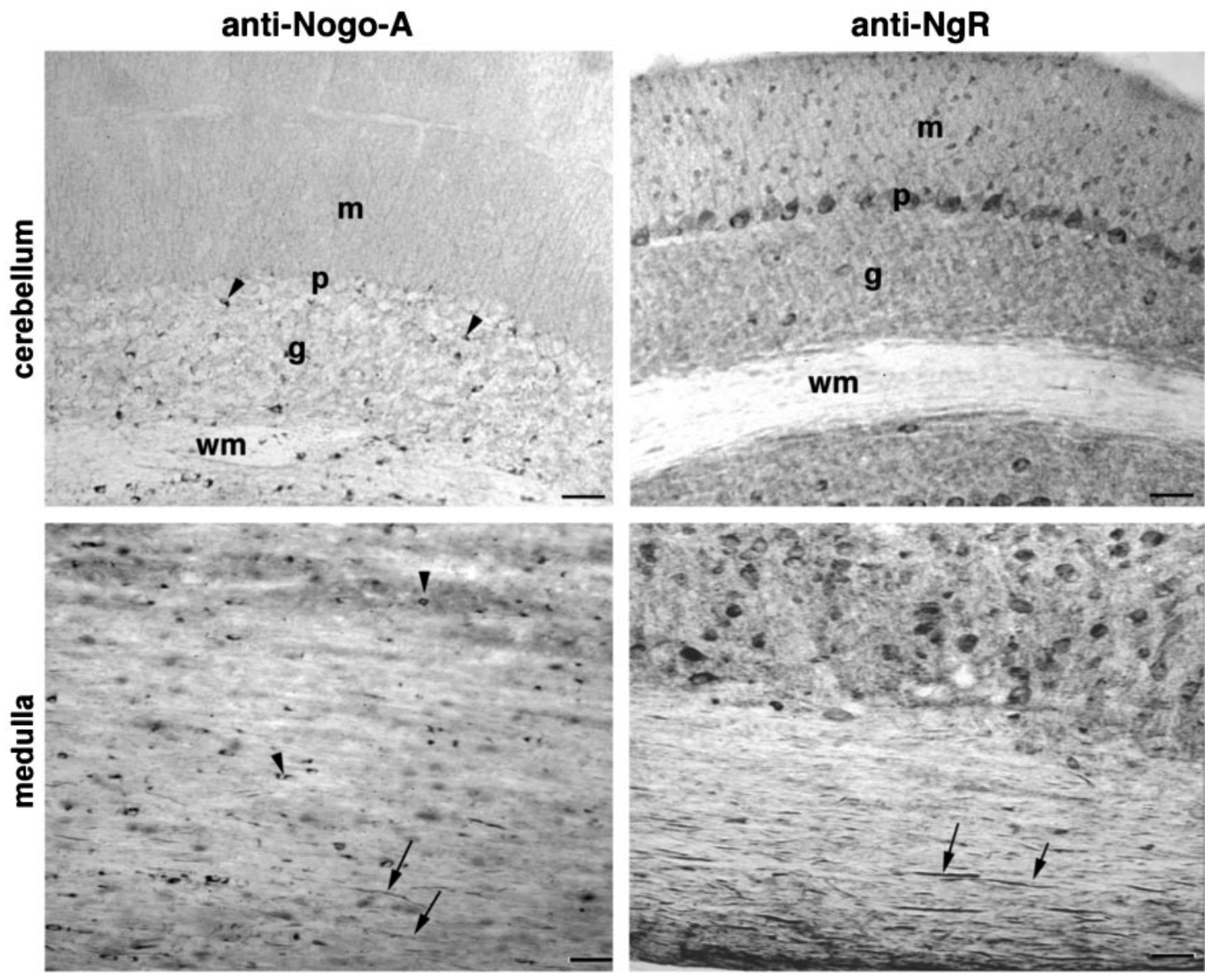

Figure 9. Presence of Nogo and $\mathrm{NgR}$ protein in the hindbrain Sagittal sections of the cerebellum and medulla oblongata were analyzed with anti-Nogo-A and anti-NgR antibodies. Oligodendrocyte cell bodies (arrowheads) and myelinated fibers (arrows) contain Nogo-A, whereas NgR immunoreactivity is present in numerous neuronal cell bodies, including Purkinje cells and myelinated fibers (arrows). $m$, Molecular layer; $p$, Purkinje cell layer; $g$, granule cell layer; $w m$, deep white matter layer. Scale bars, $100 \mu \mathrm{m}$.

of Nogo-A and $\mathrm{NgR}$ in spinal cord supports the conclusion that the two proteins are situated in an orientation where they may interact at the axon-myelin interface.

Various regions of the CNS were examined to determine if different regions might use the Nogo-A/NgR system to different degrees. The distribution of both proteins is quite widespread in the adult mouse nervous system (Table 1). In the forebrain (Fig. 7), multiple layers of the cerebral cortex express the proteins. However, as in the spinal cord, the cellular distribution is different. $\mathrm{NgR}$ is detectable in many neuronal cell bodies and the neuropil, whereas Nogo-A is observed in oligodendrocytes and neuropil. Similarly, the hippocampus exhibits $\mathrm{NgR}$ in pyramidal cells and in dentate gyrus granule cells. Nogo-A is present only in oligodendrocyte cell bodies and in the neuropil.

Analysis of cortex at the utrastructural level reveals $\mathrm{NgR}$ at both pre- and post-synaptic sites (Fig. 8). NgR is evident presynaptically at asymmetrical synapses where the DAB reaction product distributes diffusely among cytoplasmic elements, including synaptic vesicles and mitochondria (Fig. $8 A, B$ ). In the NgRimmunoreactive postsynaptic profiles of asymmetric synapses, reaction product is evident at the postsynaptic density as well as on microtubules and mitochondria (Fig. $8 C, D$ ). No synapses with both presynaptic and postsynaptic NgR are observed. Localization of $\mathrm{NgR}$ to synaptic junctions broadens the potential roles of this molecule to include modulation of synaptic structural plasticity.
In the cerebellum, Nogo-A immunoreactivity is again prominent in oligodendrocyte cell bodies scattered in the deep white matter and the granule cell layer, with some neuropil staining (Fig. 9). In contrast, the $\mathrm{NgR}$ is expressed by multiple neurons, including Purkinje cells and granule cells, and is found throughout the neuropil.

Longitudinal sections through white matter tracts in the medulla oblongata demonstrate the same pattern seen in longitudinal sections of the spinal cord (Fig. 9). Axonal staining for $\mathrm{NgR}$ is prominent, whereas Nogo-A is visualized both in oligodendrocyte cell bodies and in myelinated fiber profiles.

The developmental regulation of Nogo-A and $\mathrm{NgR}$ was examined in mice from E15 through adulthood (Fig. 10). At E15 and P1, the forebrain exhibits strong staining for Nogo-A. The pattern is reticular, with few stained cell bodies. Because $\mathrm{NgR}$ is not yet expressed, the role of this early Nogo-A expression may relate to a Reticulon-like function rather than to a cell surface interaction with axonal $\mathrm{NgR}$. By P15, the adult Nogo-A pattern of strongly stained oligodendrocyte cell bodies becomes apparent. Developing brain samples show little or no $\mathrm{NgR}$ immunoreactivity in comparison to P15 and adult samples. This is consistent with our previous findings of late developmental expression of $\mathrm{NgR}$ in chick (Fournier et al., 2001) and with the late onset of responsiveness to axonal inhibition by CNS myelin (Cai et al., 2001).

Because the early embryonic brain demonstrates widespread 

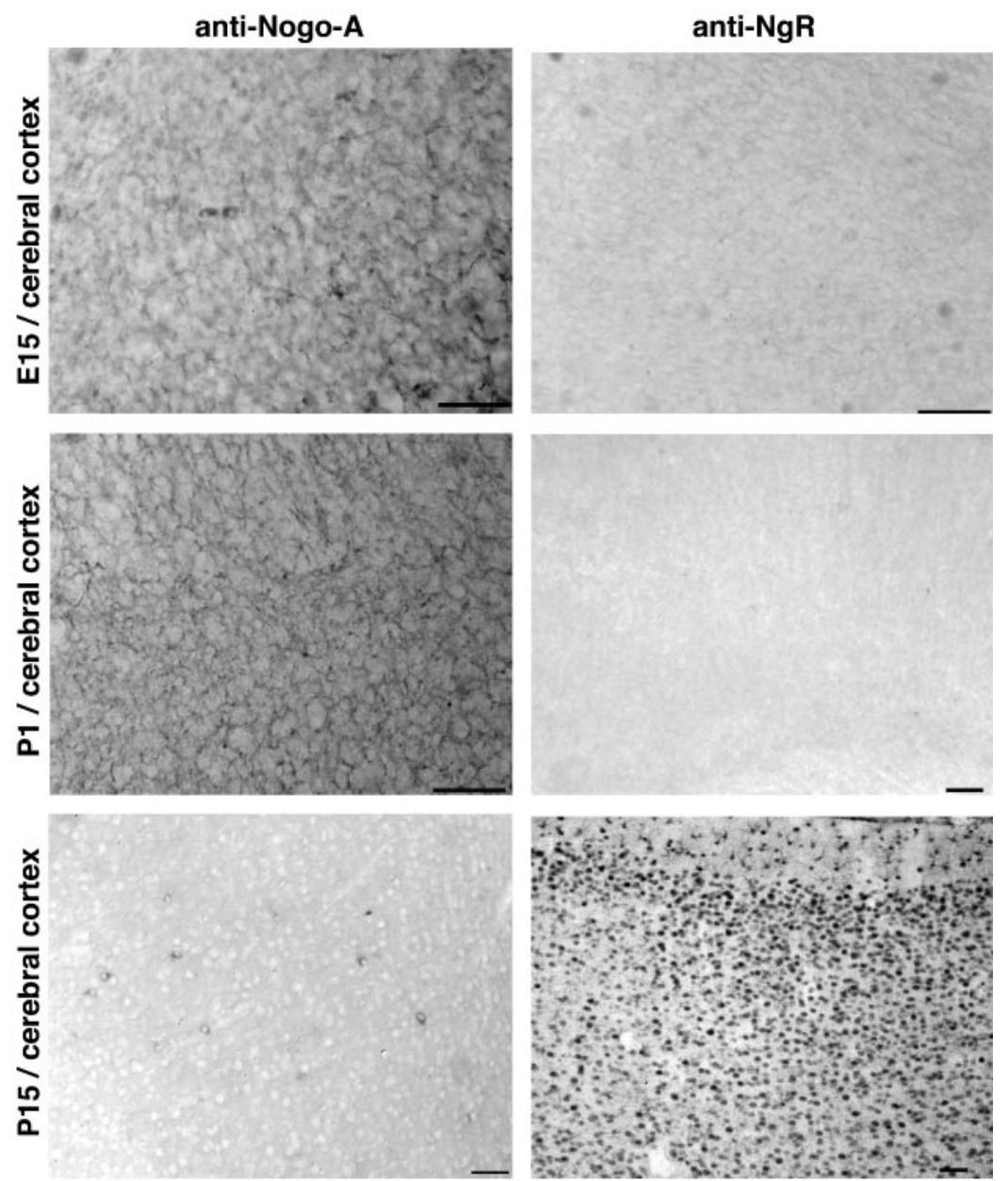

Figure 10. Developmental pattern of Nogo-A and NgR expression in the forebrain. Sections of the indicated tissues from mice of the indicated ages were stained for Nogo-A or $\mathrm{NgR}$ protein. Note the shift of Nogo-A immunoreactivity from a diffuse reticular pattern at E15 to a predominantly oligodendrocyte pattern in the adult. $\mathrm{NgR}$ is present only at low levels before birth but is widely expressed in neurons postnatally. Scale bars, $100 \mu \mathrm{m}$.
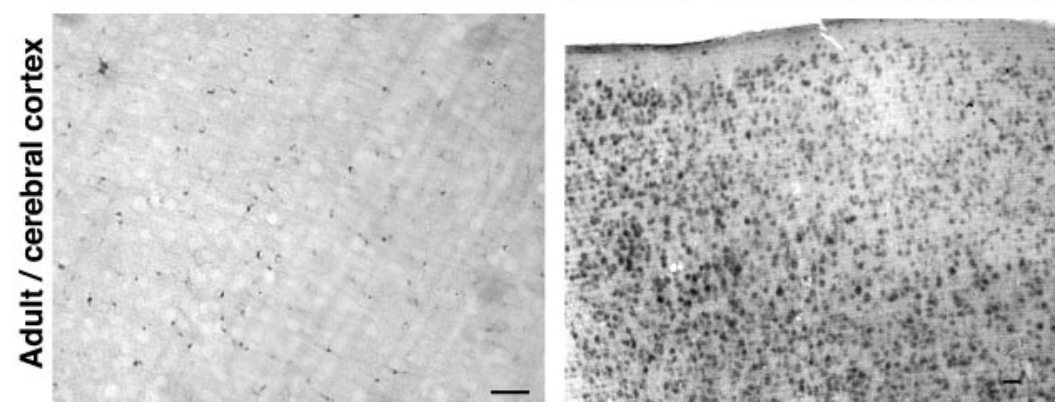

Nogo-A expression, myelin-forming cells of the adult brain may express the protein from the earliest precursor stage through that of fully mature oligodendrocytes. Alternatively, Nogo-A expression may be modulated by the differentiation process. The onset of Nogo-A expression during oligodendrocyte differentiation was assessed in cultured oligodendrocytes from P2 rat forebrain (Fig. 11). Nogo-A is detected at the oligodendrocyte-type II astrocyte (A2B5-positive) precursor stage, persists through the $\mathrm{O} 4$ and $\mathrm{O} 1$ stages, and maintains high levels in fully differentiated MBP-positive oligodendrocytes. Thus, Nogo-A protein is present at all stages of oligodendrocyte differentiation.

Mouse embryos were also examined for peripheral Nogo-A expression (Fig. 12). Sections of the developing E15 embryo reveal peripheral nerve Nogo-A that colocalizes with neurofilament. Obvious skeletal muscle Nogo-A is present at this stage, but not in the adult. $\mathrm{NgR}$ expression is nil at these stages (data not shown).

Because the Nogo-NgR interaction at the axon-myelin interface may limit axonal regeneration after trauma, it is critical to consider whether basal expression is altered after injury. Complete spinal cord transections were made at the T6 level, and protein expression was examined at various times thereafter. The expression of $\mathrm{NgR}$ at the spinal cord injury site and in the cerebral cortex did not change significantly (data not shown). In contrast, there was a moderate increase in Nogo-A staining around the injury site (Fig. 13). This was prominent at 1 week after injury and declined to baseline levels by 1 month after injury. The increased expression of Nogo-A was not present within the scarred area itself but in the region $5 \mathrm{~mm}$ caudal and rostral to the injury. In fact, the glial scar exhibits decreased Nogo-A immunoreactivity. At the cellular level, 

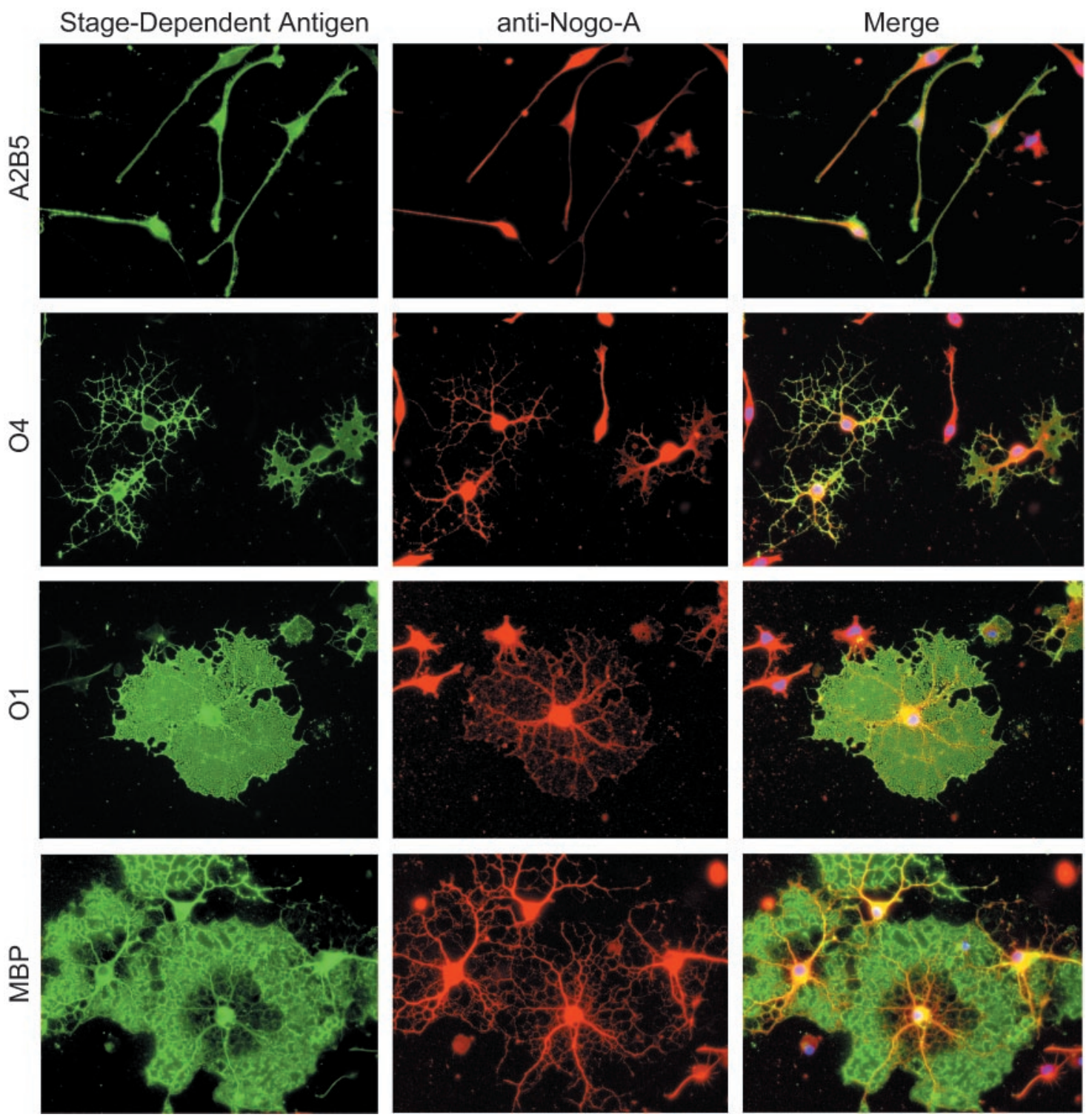

Figure 11. Nogo-A expression during oligodendrocyte differentiation. Oligodendrocyte precursors isolated from rat forebrain were differentiated in vitro and stained for the stage-dependent antigens recognized by A2B5, O4, O1, and anti-MBP antibodies (green). Nogo-A immunoreactivity is observed in double-stained cells from each stage of oligodendrocyte differentiation (red). The merged images include nuclear staining (blue) by propidium iodide.

numerous small cells in the perilesional area were positive for Nogo-A.

\section{DISCUSSION}

The distribution of NgR and Nogo-A supports the hypothesis that these two proteins interact at contact sites between axons and myelin. A majority of Nogo-A is expressed by oligodendrocytes in the adult $\mathrm{CNS}$, and a proportion of the protein localizes to the adaxonal membrane. The $\mathrm{NgR}$ protein is found throughout axons in the adult and maturing CNS. Expression of $\mathrm{NgR}$ is minimal before myelination. The juxtaposed expression of this ligandreceptor pair is detected in the uninjured brain and spinal cord, and there is a modest increase in Nogo-A expression at sites of trauma.

The adjacent cellular expression of Nogo-A and $\mathrm{NgR}$ in the intact brain is consistent with the hypothesis that Nogo-A limits axonal sprouting and plasticity as part of normal physiology. A general statement of this theory holds that axon growth and pathfinding are robust during development. After synaptogenesis and myelination, axonal contacts with Nogo-A and other myelinderived outgrowth inhibitors may serve to stabilize major myelinated tracts. Several major lines of evidence now support this notion: (1) $\mathrm{NgR}$ is expressed on mature axons and Nogo-A is present at the adaxonal oligodendrocyte membrane (this manuscript); (2) Nogo-66 limits axonal growth in vitro via the $\mathrm{NgR}$ protein (GrandPre et al., 2000; Fournier et al., 2001); and (3) the IN-1 antibody recognizing Nogo-A and other proteins promotes sprouting from uninjured tracts adjacent to sites of trauma (Thallmair et al., 1998; Z'Graggen et al., 2000; Raineteau et al., 2001). The widespread distribution of the NgR-Nogo-A system in the adult CNS indicate that this may apply to most, if not all, neurons.

After trauma, the anatomical correlation of Nogo-A and $\mathrm{NgR}$ distribution persists. If anything, Nogo-A expression in perilesional areas is increased. Further studies will be required to define the cell of origin for the increased Nogo-A, although 

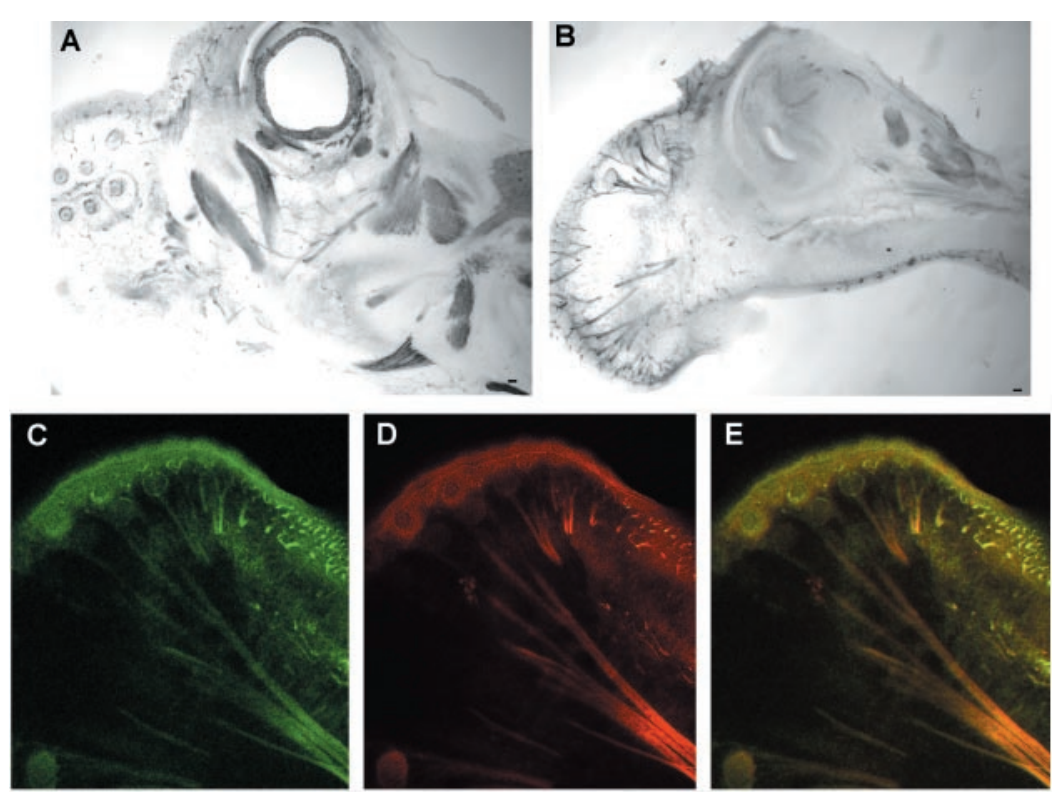

Figure 12. Peripheral expression of Nogo-A in E15 mouse embryo. $A, B$, Parasagittal sections of the head of the E15 mouse embryo were stained for Nogo-A expression. Note the strong skeletal muscle expression of Nogo-A in $A$ and the nerve fiber expression in $B$. Anterior is to the left, dorsal is up. $C-E$, Nogo-A $(C, E$, green $)$ and neurofilament $(D, E$, red $)$ are colocalized in a section similar to that in $B$. The presence of Nogo-A in neurofilament-positive structures is clear. $F$, Higher magnification of $A$ reveals a Nogo-A-positive nerve fiber innervating a Nogo-A-positive muscle. $G$, Adult skeletal muscle expresses little or no Nogo-A protein as compared with the high level E15 expression in $F$. Scale bars, $100 \mu \mathrm{m}$.
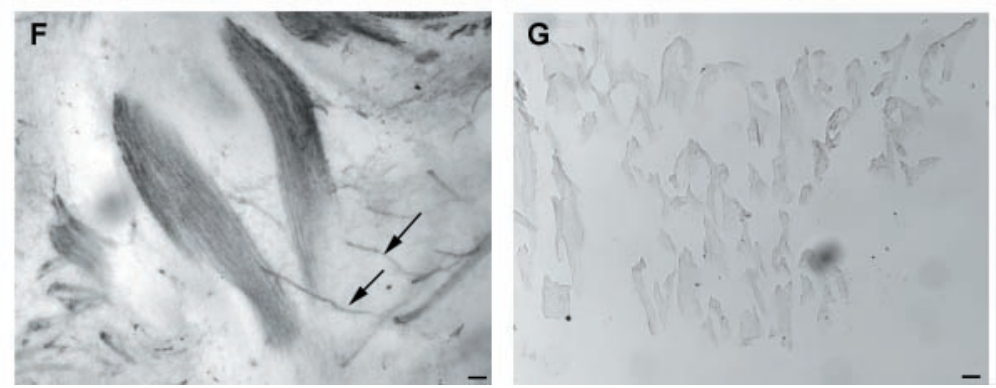
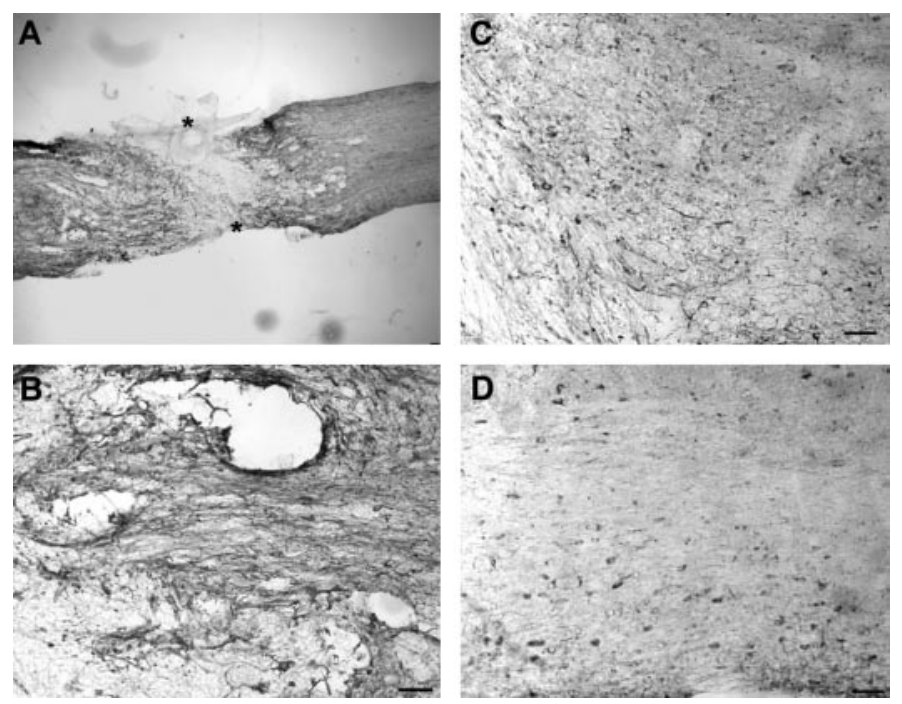

Figure 13. Nogo-A in transected adult spinal cord. Parasagittal sections of the thoracic spinal cord were processed for Nogo-A $(A)$ immunohistology 1 week after complete spinal cord transection (asterisk). Note the moderate increase of Nogo-A in the region immediately surrounding the lesion site and the low level within the glial scar. Higher magnification of the perilesional site stained for Nogo-A at 1 week $(B), 2$ weeks $(C)$, or 1 month after injury $(D)$. Scale bars, $100 \mu \mathrm{m}$.

proliferating NG2-positive cells are a potential source (McTigue et al., 2001). Thus, the anatomical studies support the notion that the NgR-Nogo-A pathway participates in the extreme limitation of axonal regeneration observed in the adult mammalian CNS.
The data are consistent with the ability of the IN-1 antibody to promote some degree of axonal regeneration (Bregman et al., 1995; Merkler et al., 2001).

$\mathrm{NgR}$ is also detected at synapses in the adult CNS. This finding raises the possibility that the Nogo and $\mathrm{NgR}$ might contribute to structural plasticity at synapses as well as along axonal pathways. Because it is now clear that many forms of activity-dependent synaptic plasticity are associated with structural rearrangements (Engert and Bonhoeffer, 1999; Yuste and Bonhoeffer, 2001), it is plausible that some of the same mechanisms may contribute to axonal rearrangements and dendritic spine rearrangements. The potential role of $\mathrm{Nogo}-\mathrm{NgR}$ in such events has not yet been explored in functional studies.

$\mathrm{NgR}$ protein is primarily expressed by neurons of the adult animal in a distribution where it may receive a Nogo signal. In contrast, Nogo-A is expressed in many tissues exhibiting little or no $\mathrm{NgR}$ expression. For example, high levels of Nogo-A are present in developing skeletal muscle and in embryonic neurons. The role of Nogo-A in these locations appears unrelated to its role as a ligand for $\mathrm{NgR}$. The simplest explanation for $\mathrm{NgR}$ independent expression of Nogo-A is that the protein subserves a second function in these tissues. This second function may be derived from the sequence homology between Reticulons and Nogo (GrandPre et al., 2000). The nature of Reticulon function remains elusive, but by virtue of their subcellular localization, these proteins are thought to participate in endoplasmic reticulum regulation (van de Velde et al., 1994; GrandPre et al., 2000). Alternatively, Nogo may regulate cellular survival in developing muscle and nerve, because Nogo-B has recently been shown to 
modulate apoptosis in some cancer cells (Tagami et al., 2000; Li et al., 2001).

Taken together, the data presented here support the notion that Nogo-A interaction with $\mathrm{NgR}$ limits axonal regeneration after injury. In addition, the juxtaposed distribution of these proteins in uninjured brain is consistent with the participation of this system in maintaining axonal tract stability and perhaps in modulating synaptic structural plasticity. $\mathrm{NgR}$ expression is consistent with a specific role in receiving Nogo signals, whereas Nogo may have additional roles unrelated to $\mathrm{NgR}$ in early development of multiple tissues, including brain and skeletal muscle.

\section{REFERENCES}

Benfey M, Aguayo AJ (1982) Extensive elongation of axons from rat brain into peripheral nerve grafts. Nature 296:150-152.

Bregman BS, Kunkel-Bagden E, Schnell L, Dai HN, Gao D, Schwab ME (1995) Recovery from spinal cord injury mediated by antibodies to neurite growth inhibitors. Nature 378:498-501.

Brittis PA, Flanagan JG (2001) Nogo domains and a Nogo receptor: implications for axon regeneration. Neuron 30:11-14.

Cai D, Qiu J, Cao Z, McAtee M, Bregman BS, Filbin MT (2001) Neuronal cyclic AMP controls the developmental loss in ability of axons to regenerate. J Neurosci 21:4731-4739.

Chen MS, Huber AB, van der Haar ME, Frank M, Schnell L, Spillmann AA, Christ F, Schwab ME (2000) Nogo-A is a myelin-associated neurite outgrowth inhibitor and an antigen for monoclonal antibody IN-1. Nature 403:434-439.

David S, Aguayo AJ (1981) Axonal elongation into peripheral nervous system "bridges" after central nervous system injury in adult rats. Science 214:931-933.

Engert F, Bonhoeffer T (1999) Dendritic spine changes associated with hippocampal long-term synaptic plasticity. Nature 399:66-70.

Fournier AE, Strittmatter SM (2001) Repulsive factors and axon regeneration in the CNS. Curr Opin Neurobiol 11:89-94.

Fournier AE, Nakamura F, Kawamoto S, Goshima Y, Kalb RG, Strittmatter SM (2000) Semaphorin3A enhances endocytosis at sites of receptor-F-actin colocalization during growth cone collapse. J Cell Biol 149:411-422.
Fournier AE, GrandPre T, Strittmatter SM (2001) Identification of a receptor mediating Nogo-66 inhibition of axonal regeneration. Nature 409:341-346.

GrandPre T, Nakamura F, Vartanian T, Strittmatter SM (2000) Identification of the Nogo inhibitor of axon regeneration as a Reticulon protein. Nature 403:439-444.

Li Q, Qi B, Oka K, Shimakage M, Yoshioka N, Inoue H, Hakura A, Kodama K, Stanbridge EJ, Yutsudo M (2001) Link of a new type of apoptosis-inducing gene ASY/Nogo-B to human cancer. Oncogene 20:3929-3936.

McTigue DM, Wei P, Stokes BT (2001) Proliferation of NG2-positive cells and altered oligodendrocyte numbers in the contused rat spinal cord. J Neurosci 21:3392-3400.

Merkler D, Metz GA, Raineteau O, Dietz V, Schwab ME, Fouad K (2001) Locomotor recovery in spinal cord-injured rats treated with an antibody neutralizing the myelin-associated neurite growth inhibitor Nogo-A. J Neurosci 21:3665-3673.

Prinjha R, Moore SE, Vinson M, Blake S, Morrow R, Christie G, Michalovich D, Simmons DL, Walsh FS (2000) Inhibitor of neurite outgrowth in humans. Nature 403:383-384.

Raineteau O, Fouad K, Noth P, Thallmair M, Schwab ME (2001) Functional switch between motor tracts in the presence of the mAb IN-1 in the adult rat. Proc Natl Acad Sci USA 98:6929-6934.

Richardson PM, McGuinness UM, Aguayo AJ (1980) Axons from CNS neurons regenerate into PNS grafts. Nature 284:264-265.

Tagami S, Eguchi Y, Kinoshita M, Takeda M, Tsujimoto Y (2000) A novel protein, RTN-XS, interacts with both Bcl-XL and Bcl-2 on endoplasmic reticulum and reduces their anti-apoptotic activity. Oncogene 19:5736-5746.

Thallmair M, Metz GA, Z'Graggen WJ, Raineteau O, Kartje GL, Schwab ME (1998) Neurite growth inhibitors restrict plasticity and functional recovery following corticospinal tract lesions. Nat Neurosci $1: 124-131$.

van de Velde HJ, Roebroek AJ, van Leeuwen FW, Van de Ven WJ (1994) Molecular analysis of expression in rat brain of NSP-A, a novel neuroendocrine-specific protein of the endoplasmic reticulum. Brain Res Mol Brain Res 23:81-92.

Vartanian T, Goodearl A, Viehover A, Fischbach G (1997) Axonal neuregulin signals cells of the oligodendrocyte lineage through activation of HER4 and Schwann cells through HER2 and HER3. J Cell Biol 137:211-220.

Yuste R, Bonhoeffer T (2001) Morphological changes in dendritic spines associated with long-term synaptic plasticity. Annu Rev Neurosci 24:1071-1089.

Z'Graggen WJ, Fouad K, Raineteau O, Metz GA, Schwab ME, Kartje GL (2000) Compensatory sprouting and impulse rerouting after unilateral pyramidal tract lesion in neonatal rats. J Neurosci 20: 6561-6569. 